Narrative Medicine and Community-Based Health Care and Planning 
John W. Murphy • Berkeley A. Franz Jung Min Choi • Karen A. Callaghan

\section{Narrative Medicine and Community-Based Health Care and Planning}

黛 Springer 
John W. Murphy

Department of Sociology

University of Miami

Coral Gables, FL, USA

Jung Min Choi

Department of Sociology

San Diego State University

San Diego, CA, USA

\author{
Berkeley A. Franz \\ Department of Social Medicine \\ Ohio University Heritage College \\ of Osteopathic Medicine \\ Athens, OH, USA
}

Karen A. Callaghan

Dean, College of Arts \& Sciences

Barry University

Miami Shores, FL, USA

ISBN 978-3-319-61856-2

ISBN 978-3-319-61857-9 (eBook)

DOI 10.1007/978-3-319-61857-9

Library of Congress Control Number: 2017944719

(C) Springer International Publishing 2017

This work is subject to copyright. All rights are reserved by the Publisher, whether the whole or part of the material is concerned, specifically the rights of translation, reprinting, reuse of illustrations, recitation, broadcasting, reproduction on microfilms or in any other physical way, and transmission or information storage and retrieval, electronic adaptation, computer software, or by similar or dissimilar methodology now known or hereafter developed.

The use of general descriptive names, registered names, trademarks, service marks, etc. in this publication does not imply, even in the absence of a specific statement, that such names are exempt from the relevant protective laws and regulations and therefore free for general use.

The publisher, the authors and the editors are safe to assume that the advice and information in this book are believed to be true and accurate at the date of publication. Neither the publisher nor the authors or the editors give a warranty, express or implied, with respect to the material contained herein or for any errors or omissions that may have been made. The publisher remains neutral with regard to jurisdictional claims in published maps and institutional affiliations.

Printed on acid-free paper

This Springer imprint is published by Springer Nature

The registered company is Springer International Publishing AG

The registered company address is: Gewerbestrasse 11, 6330 Cham, Switzerland 


\section{Preface}

Public health care is needed now more than ever. The point of this statement is that all persons should have access to health care, in a systematic manner, regardless of the ability to pay. But equally important is that this care should meet the needs of individuals and communities, and be provided in a timely and relevant way. At least since 1978, and the Alma Ata Conference, and subsequent Declaration, successful public health care is understood to depend on local participation, and eventual control, of these services.

As will be discussed throughout this book, this involvement should extend beyond the usual consultations and solicitations for input. Furthermore, participation is expected to extend beyond the usual education and prevention campaigns. What is required, accordingly, is that local knowledge be used to frame problems, construct interventions, implement these programs, and evaluate all outcomes. In this way, relevant questions will likely be asked and pertinent proposals and solutions generated.

Equally important, however, is that local persons guide these efforts. Participation, in this case, signals control; in other words, local persons direct all health initiatives. The thrust of this recommendation is to energize communities, so that they begin to identify and solve their problems. These persons replace the usual cadre of professionals and become the experts. Many models exist-ranging from health promoters to health committees - that demonstrate these locals, with some training and other support, can carry out complex tasks that improve dramatically the health status of persons, while rallying communities.

The aim of this book, accordingly, is to illustrate how narrative medicine, a relatively new development, can facilitate public health care. Fundamental to this approach to medicine is the proposition that both individuals and communities tell stories about themselves that are vital to identifying properly the meaning of, for example, illness, care, and health outcomes. Without this knowledge interventions will be poorly designed and haphazard. What persons say about their problems and situations matters with respect to improving the relevance, effectiveness, and sustainability of health programs. These narratives, stated simply, provide vital insight into the lives of those who need treatment. 
But perhaps most important about public health care is the humanitarian character of this strategy. Specifically noteworthy is that local persons become directly involved in caring for one another. In a world that is rife with alienation such sensitivity is truly needed and revolutionary. Mutual care, accordingly, might gradually come to replace the hostility that seems to be rampant. In other words, the lessons that can be learned from the accompanying dialogue and mutual respect that are encouraged can be expanded far beyond health care. Perhaps even widespread social solidarity can be generated.

The politics of public health care are thus fairly clear. That is, health care is a public undertaking! The public is not merely the focus but should control the delivery of services. And perhaps in time, when mutual care is normative, the public will become instrumental in directing other key institutions. Indeed, a sense of community might be established that is increasingly inclusive and supportive. The world would thus truly be improved.

Coral Gables, FL

John W. Murphy

Athens, $\mathrm{OH}$

Berkeley A. Franz

San Diego, CA

Jung Min Choi

Miami Shores, FL

Karen A. Callaghan

April 2017 


\section{Contents}

1 Introduction: Narratives, Local Knowledge, and World Entry . . . . 1

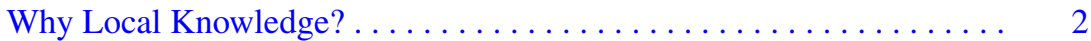

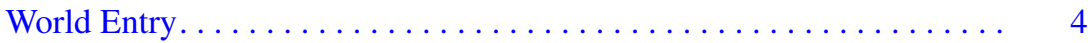

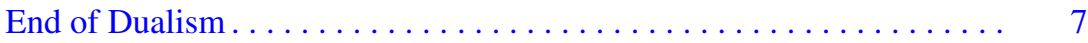

Narratives Are Everywhere. . . . . . . . . . . . . . . . . . 9

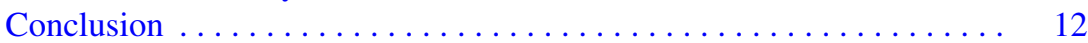

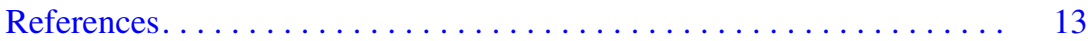

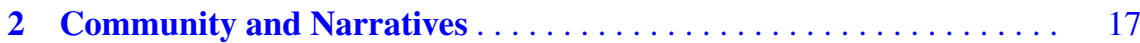

The Linguistic Turn. . . . . . . . . . . . . . . . . . . . . . 19

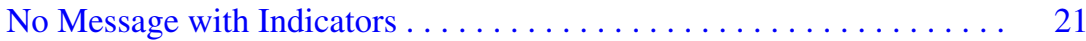

The Elusive Community . . . . . . . . . . . . . . . . . . . 23

Narratives and Public Health Care ... . . . . . . . . . . . . 25

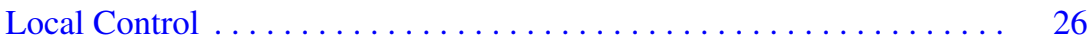

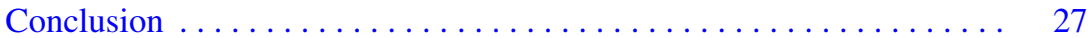

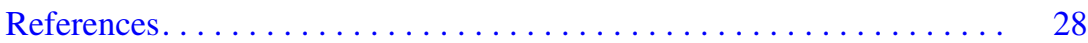

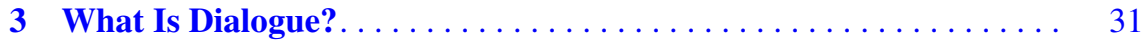

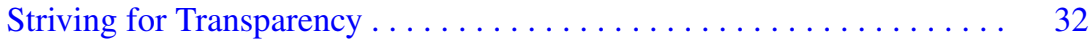

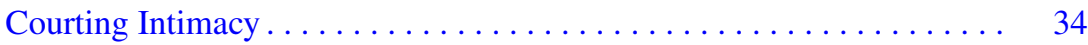

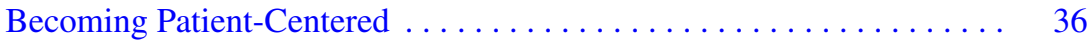

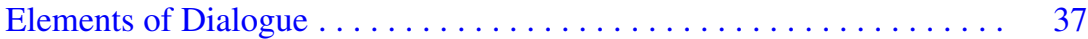

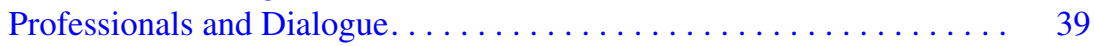

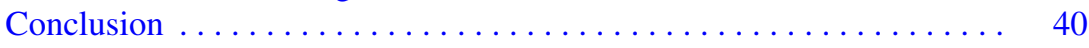

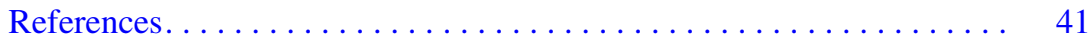

4 Storylines, Causes, and the Locus of Interventions . . . . . . . . . . 45

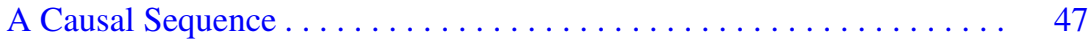

A Narrative Framework . . . . . . . . . . . . . . . . . . . . . 49

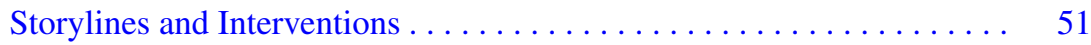

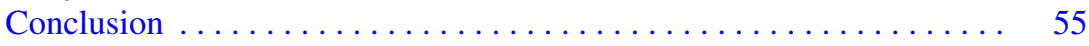

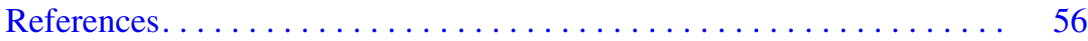


5 Narratives, Methods, and World Entry ............... 59

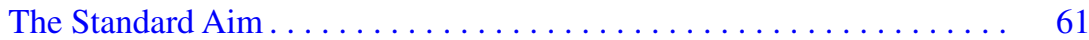

Thrown into the World $\ldots \ldots \ldots \ldots \ldots \ldots \ldots \ldots \ldots \ldots \ldots \ldots$

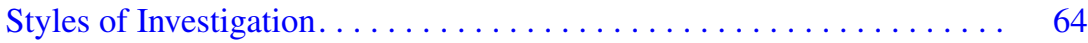

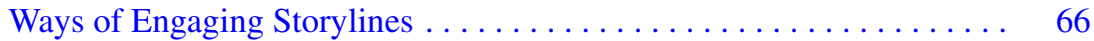

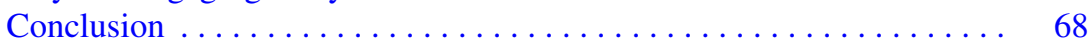

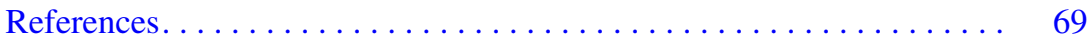

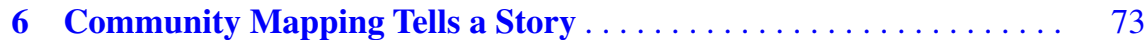

What Does a Typical Map Do $\ldots \ldots \ldots \ldots \ldots \ldots \ldots \ldots \ldots$

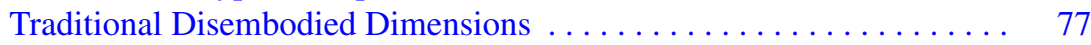

Embodied Dimensions . . . . . . . . . . . . . . . . . . . . . 79

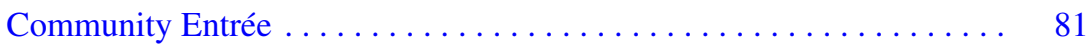

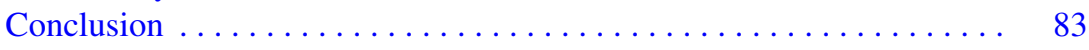

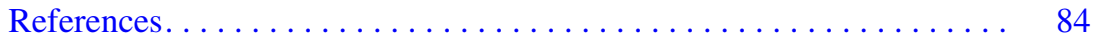

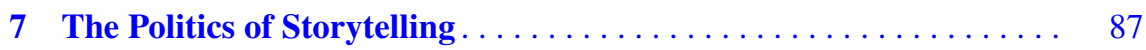

Questions About Dialogue . . . . . . . . . . . . . . . . . . 89

Medicine and Realism. . . . . . . . . . . . . . . . . . . 90

The Road to Democratization . . . . . . . . . . . . . . . . . . 92

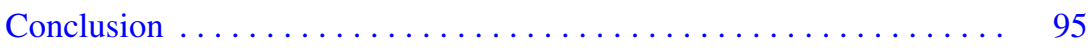

References............................. 97

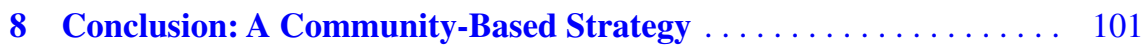

Why Community-Based? . . . . . . . . . . . . . . . . . . . 102

Becoming Community-Based Through Narratives. . . . . . . . . . . 103

Narratives and Change . . . . . . . . . . . . . . . . . . . 107

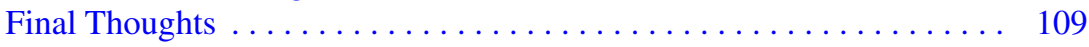

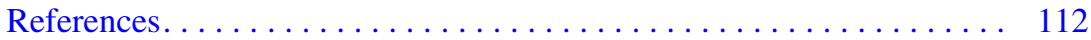

Bibliography $\ldots \ldots \ldots \ldots \ldots \ldots \ldots \ldots \ldots \ldots \ldots \ldots \ldots \ldots \ldots \ldots$

Author Index . . . . . . . . . . . . . . . . . . . . . . . . . . . . . . . . . . . 129

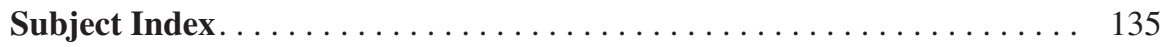




\section{About the Authors}

John W. Murphy received his Ph.D. from Ohio State University. He is currently Professor of Sociology at the University of Miami. His areas of interest are social philosophy and community health care.

Berkeley A. Franz received her Ph.D. from the University of Miami. She is currently Assistant Professor of Community-based Health at Ohio University's Heritage College of Osteopathic Medicine. Her areas of interest are community-based health care, health policy, and religion and health.

Jung Min Choi received his Ph.D. from the University of York, Canada. He is currently Associate Professor of Sociology at San Diego State University. His areas of interest are sociological theory, education, and health care.

Karen A. Callaghan received her Ph.D. from Ohio State University. She is currently Professor of Sociology and Dean of the College of Arts and Sciences at Barry University. Her areas of interest are sociological theory and community planning. 